pathways, future field studies of mantle dunite may provide key constraints on the distribution and dimensions of asthenospheric melt channels. Understanding the role and origin of mantle dunite will also require determination of the integrated flux of melt through these channels. Kelemen et al. estimate that the volume of melt percolating through the dunite pods may exceed the dunite volume by a factor of 10 , and that locally it may reach a factor of 300-400, but additional field and theoretical studies are needed to generate robust constraints. Metamorphic petrologists have developed techniques for calculating integrated water/rock ratios from petrological observations, and analogous geochemical tests for determining integrated basalt/dunite ratios should be sought. Also, it is not yet established whether porous dunite channels can deliver melt from the site of melting to the surface on the thousand-year timescale required by observed ${ }^{226} \mathrm{Ra}-{ }^{230} \mathrm{Th}-{ }^{238} \mathrm{U}$ disequilibria in MORB (ref. 5).

Finally, evidence that dunite channels equilibrate with MORB-like basalt sheds light on the locus of MORB aggregation and mixing, but also raises questions about the role of dunite bodies as melt pathways. Melting in the sub-ridge mantle is a fractional process that should generate an exceptionally wide range of liquid compositions ${ }^{6}$. As MORBs do not reflect much of this compositional variability, they must be products of extensive mixing processes. It is commonly assumed that much of this blending takes place in lithospheric magma chambers, but there are few constraints on magma mixing in the asthenosphere.

The mineral chemistry of the Oman dunite pods indicates that extensive mixing takes place during transport in the asthenosphere and that MORB gains much of its geochemical character before it enters the lithosphere. On the other hand, melt inclusions in olivine phenocrysts from MORB commonly preserve both ultra-depleted and ultra-enriched liquids that have experienced little or no mixing ${ }^{7,8}$. The unmixed character of these inclusions suggests that some melts are delivered from disparate parts of the melting regime to the lithosphere by processes different from those recorded in the Oman dunite pods. The evidence from Oman shows that dunite channels are significant melt pathways in the asthenosphere. But they may not be the only ones.

Marc Hirschmann is at the California Institute of Technology, and the Department of Geology, University of North Carolina, Chapel Hill, North Carolina 27599, USA.

1. Kelemen, P. B., Shimizu, N. \& Salters, V. J. M. Nature 375 747-753 (1995)

2. Kelemen, P. B., Whitehead, J. A., Aharanov, E. \& Jordahl, K. A. J. geophys. Res. 100, 475-496 (1995)

3. Barcilon, V. \& Lovera, O. J. Fluid Mech. 204, 121-133 (1989).

4. Stevenson, D. Geophys. Res. Lett. 16, 1067-1070 (1989).

5. Rubin, K. H. \& MacDougall, J. D. Nature 335, 158-161 (1989)

6. Johnson, K. T. M., Dick, H. J. B. \& Shimizu, N.J. geophys. Res. 95, 2661-2678(1990)

7. Shimizu, N. Min. Mag. 58A, $829-830$ (1994).

8. Sobolev, A. V. \& Shimizu, N. Nature 363, 151 (1993)

OBITUARY

\title{
Raymond Lyttleton (1911-95)
}

THE death on 16 May of Raymond Arthur Lyttleton opens a large gap in the collective knowledge of the British astronomical community. For Ray Lyttleton, essentially alone, held at his fingertips the celestial mechanics of Newton's succes. sors in the nineteenth century. In particular, his knowledge of the theory of the Moon's motion, the only problem which Newton said had ever made his head ache, was without compare among his colleagues. In his career, spent from 1969 as professor of theoretical astron. omy at the University of Cambridge, Lyttleton ranged widely, tackling issues in both cosmology and geophysics.

It was never clear, even to those who knew him well, whether his research interests were decided by a sense of style or whether in his early years it was the research that developed the style. Most scientists tend to stumble towards a problem, gradually clarifying their perceptions of it as time goes on. Lyttleton, on the other hand, chose investigations where he could begin with issues that were clearly and explicitly defined, putting himself in the position of a student who is called upon to solve an especially taxing problem in some celestial mathematical examination.

But the exam was invariably without a time limit. For a problem that was hard enough and interesting enough, he was prepared to go on trying for a solution over decades of effort. It was so with the question of the rotational instability of an incompressible fluid, which had caused difficulty for mathematicians as diverse as Jacobi, Poincaré and Jeans. The culmination of this work was published as The Stability of Rotating Liquid Masses in 1953.

Lyttleton's interests in astrophysics

\section{IMAGE UNAVAILABLE FOR COPYRIGHT REASONS}

were mainly concerned with situations in which he considered that dynamics had an important role to play, as in the relationship between the gravitational field of a star and the interstellar gas through which it moves. Such an interplay causes the stars to be open systems, a view that seemed strange when it was first advanced at the beginning of the 1940 s. Here again the accretion problem, as it has become called, continued to be investigated in its fundamentals for two decades or more after the Second World War. And in its practical details it has continued to influence astrophysics.

Lyttleton's contribution to the understanding of the highly complex practical dynamics problem of the flight of a cricket ball has become well known. Almost alone among mathematicians with an interest in ball games, he was a considerable practical performer in his own right (though finding it difficult to devote as much time to sport as perhaps he would have liked).

There were few who knew Lyttleton who did not at some stage encounter the razor edge of his wit. He delighted in pointing out self-contradictions in the rules governing organizations with a high measure of formal respectability clubs, learned societies, colleges and the like. Yet, paradoxically enough, he was thoroughly formal himself on formal occasions. And so far from being a dangerous customer, as many took him to be, when called on to occupy various posts he discharged them with a minimum of difficulty and fuss - as when for a number of years he was the Secretary of the Faculty of Mathematics at Cam. bridge, and Geophysical Secretary of the Royal Astronomical Society.

On almost all matters, whether in science or out, Ray Lyttleton had his own way of looking at things. One can say without fear of error that he never sought to enhance his reputation by believing what he was told.

Fred Hoyle

Sir Fred Hoyle was formerly the Director of the Institute of Theoretical Astronomy, Cambridge, UK. 